\title{
SEEKING INSIGHTS INTO AN UNKNOWN FUTURE: EXPLORING DESIGNERS' STRATEGIES TO DISCOVER KEY INSIGHTS
}

\author{
Knudsen, Line Sand; Haase, Louise Møller \\ Aalborg University
}

\begin{abstract}
Insights play a significant role in creation of new products. Insights provide the designer with an understanding of the user, market, technologies and trends, and how these might change over time. This information is critical for the designer to get an understanding of how and why present products succeed or fail. Hence, insights serve as both triggers and drivers for envisioning future products, but they are also fundamental to ensure that new products created will provide meaningful experiences to the users. In design literature, there is a significant amount of research on how to gather information about the user, market, trends, etc. However, very little research is focused on how the designer addresses this information to discover or uncover key insights. Through interviews with expert designers behind twelve products, we identified three strategies that designers use to discover insights. We found that designers search for insights that could be used to: 1) establish the product's future identity, 2) identify core challenges based on the new identity in the existing user experience and 3) identify solutions that could meet the core challenges and accentuate the new identity.
\end{abstract}

Keywords: Design insights, Early design phases, Design practice, New product development

Contact:

Knudsen, Line Sand

Aalborg University

Department of Architecture, Design \& Media Technology

Denmark

1sk@create.aau.dk

Cite this article: Knudsen, L.S., Haase, L.M. (2019) 'Seeking Insights into an unknown Future: Exploring Designers' Strategies to Discover Key Insights', in Proceedings of the 22nd International Conference on Engineering Design (ICED19), Delft, The Netherlands, 5-8 August 2019. DOI:10.1017/dsi.2019.407 


\section{INTRODUCTION}

Nowadays users are increasingly consuming products not only for their practical reasons but also for their meaning (Ravasi \& Rindova 2008). A meaningful product is defined as "an object that symbolically expresses the integration of the owner with his/her social context" (Csikszentmihalyi \& Rochberg-Halton 1981, p. 39). In this perspective, design is defined as an activity of meaning-making (Ylirisku et al., 2009; Harrison et al., 2007), in which future products' social and cultural meanings define the centre of focus for designers (Ravasi \& Rindova 2008). Insights are one of the key sources in this process (Brown 2009) and discovering novel insights is therefore a fundamental design activity. Designers use insights to develop an understanding of the user, the market, societal changes, new technologies, trends, etc. (Buijs 2012). This information is critical for the designer to get an idea of how and why present products succeed or fail, and to ensure that new products created will provide meaningful experiences and real value to the user. In this sense, insights serve as both triggers and drivers for envisioning future products' meaning and relevance and thus have a crucial impact on the final outcome (Yuan \& Hsieh 2015). The ability to discover or uncover novel insights and identify relevant information for the design situation is a key skill of designing; accordingly, design has increasingly focused on how to gather information about complex existing environments (Kolko 2011). Today, methods to collect insights are plentiful (e.g. shadowing, contextual interviews, personas, cultural probes, stakeholder maps, scenarios, co-creation, etc.).

\subsection{Ethnographic practice in design}

The concept of insight stems from the field of ethnography and due to this fact, many methods to gather insights in design are based on the ethnographical tradition. Today, ethnography is generally acknowledged as an especially effective approach to gain insights into customers' lives, experiences, routines and behaviours (Cooper \& Evans 2006). Back in the 1970s, the design field became aware of the value of ethnography, particularly to get a better understanding of users and the context. Since the 1980s, ethnographical research has been integrated in the HCI (Human Computer Interaction) community; and in the early 1990s, ethnographic methods were introduced to industrial design and product development (Otto \& Smith 2013). Since then designers have used ethnographical methods as an integrated part of the design process.

Indeed, ethnography is a valuable resource for design in the context of discovering novel insights. However, due to two distinct knowledge traditions and practices, insights in ethnography and design have quite different purposes and foci. In ethnography, researchers engage in long-term fieldwork to produce insights, often in one particular social and cultural setting. The aim is to observe and document comprehensively and in detail; ethnographers seek to describe the existing with the minimal impact on the people among whom they conduct their research (Otto \& Smith 2013). In contrast, designers seek to change the existing; their goal is to make impact on people's lives and behaviours (Kolko 2011). To achieve these different goals, ethnographers are driven by analysis in order to generate new knowledge and develop theory (Atkinson \& Hammersley 2007), whereas designers are clearly solution-driven (Cross 2007); their mission is to develop a future product, and therefore designers are forced to make meaning out of data quickly in order to actually design (Kolko 2011). As such, insights in the two fields have different purposes and accordingly they are generated differently: ethnography applies an inductive strategy, i.e. insights are constructed on the basis of what is empirically true. But because designers seek to understand the aspects of things that do not yet exist, they construct hypotheses about what people will do, think and feel (Kolko 2011), i.e. designers apply an abductive strategy. In this perspective, the insight discovery process in design is defined as an activity where designers iteratively attempt to link what they observe (data gathered from ethnographical methods) with what they already know (professional knowledge and personal experiences) (Kolko 2011; Yuan \& Hsieh 2015). The main differences between the two fields are summarised in Table 1 and is intended to clarify the unique practices of designing.

Table 1. Contrasts between the practices in ethnography and design

\begin{tabular}{|l|l|l|}
\hline & Ethnographers' practice & Designers' practice \\
\hline Purpose & Describe existing & Change existing \\
\hline Driver & Analysis-driven & Solution-driven \\
\hline Logic & Induction (empirical data) & Abduction (hypotheses) \\
\hline
\end{tabular}


Due to the different purposes, drivers and logics in the two fields, insights in design and ethnography are not to be defined in the same manner; insights are approached differently and they serve quite different purposes. In ethnography, researchers stop the insight discovery process when generalisations and theories can be established, based on an existing phenomenon. But in design, a further step is required: insights must be translated into a future value in terms of a product or service that will improve people's lives (Brown 2009). The complexity of a design problem is, however, that while there is no real end to it (Lawson 2005), designers must stop searching at some point. According to Kolko (2011), designers are forced to make meaning out of data quickly to actually design, which means that they must search for insights in a purposeful way. In existing literature on insights in design, a significant amount is available on methods and tools for information gathering (e.g. Schneider \& Stickdorn 2011; van Boijen et al., 2013; LUMA Institute 2012; Milton \& Rodgers 2013; Cranz 2016; Yayici 2016; Tomitsch et al., 2018; Dragt 2017). However, very little is known about how the designer addresses this information, on an operational level, to discover key insights in the meaning-making paradigm. What are designers specifically searching for when they attempt to create a new meaningful experience? It seems that designers follow a different strategy in this process compared to the ethnographic approach. Designers construct insights as a foundation upon which a future concept could be built, and therefore discovering insights is regarded as a critical step for the meaning-making process. As such, the aim of this paper is to increase understanding of designers' insight discovering strategies when they attempt to envision new meaningful products. The study is guided by the following research question: What are the strategies designers apply to discover or uncover key insights? In this attempt, we refer to 'key insights' as the designers' most important understandings of the problem, from where the concept is built. To explore the research question, we need to establish a deeper understanding of the general drivers and purposes that characterise the designers' practice (outlined in Table 1). Since these practices are embedded in the designers' general practice, they might also be apparent in their approach to insight discovering.

The paper proceeds as following: firstly, we will elaborate on the designers' practice to fully understand the context in which insights are discovered. Next, we will introduce the research design from where data is generated for this study, including introduction to the product cases. Then, the main findings of the study will be presented and finally, we will close the paper with discussion and the main conclusions of the study, as well as present implications for further work.

\section{CHARACTERISTICS OF DESIGNERS' PRACTICE}

As outlined in the introduction, the focus and purpose of insights in design is different from the traditional approach in ethnography. To fully understand the focus of designers, we found it useful to look more into the practices that characterise designers' work and thinking. This understanding is based on current literature and thus serves as the theoretical framework for this research. In the following, we will elaborate on the characteristics of designers' general practice (outlined in Table 1) which we identified as the main issues to understand the designers' strategies to insight discovery.

\subsection{Designers aim to change the existing}

The definite purpose of design is to provide products and services that improve existing situations for people and perform better than existing solutions; the designers' aim is to change the existing. Therefore, they need to develop a deep understanding of this existing context in order to identify what needs to change. In this process, it is argued that they look for critical situations or paradoxes (Dorst 2006; Christiaans 1992) to identify an opportunity that should serve the users with a better experience and value than is currently found. The paradox captures the main complexity of the situation, rather than of the problem itself. As such, the paradox represents the essence of the design situation and is defined as a 'trigger for change' that enhances creativity (Dorst 2006; Miron-Spektor et al., 2011). In a previous study of the process in creation of meaning by expert designers, Knudsen \& Haase (2018) found that the paradox is often constructed based on the designer's individual experience with an existing product that is triggered by a changed situation (observation) compared to how it was originally intended. This paradoxical situation becomes the starting point for envisioning a future meaning and experience of the product. Hekkert \& van Dijk (2011) describe this process as 'deconstruction' in which the designer evaluates the existing context for which a current product was intended. In this context, it is argued that both the emotional and functional factors are essential to identify (Brown 2009; Ulwick 2005). 


\subsection{Designers are solution-driven}

It is widely accepted that design is a solution-led process (Lee \& Evans 2012; Cross 2007; Edeholt \& Ek 2008; Lawson 2005). In practice, it means that designers do not spend much time on defining the problem as an isolated activity upfront; rather, the designer's drive is to find a solution from the user's perspective (Morrison et al., 2014). Several studies have even shown that fixation on the problem did not lead to successful outcomes (Cross 2007; Dorst \& Cross 2001). In the solution-focused strategy, designers approach the design problem by working 'backwards', i.e. they start by settling the desired outcome (compared to other sciences where the problem and all its nuances must first be analysed before the it can be solved). In design, the process starts from the value to achieve and then the designer searches for possible solutions to attain this value in the best way (Dorst 2015).

\subsection{Designers reason through abduction}

In design literature, it is further widely described that design problems are ill-defined. This means that in a design project, it is not clear what the problem is and therefore there might be many possible solutions. Rittel and Webber (1973) argue that "there is no definitive formulation of a wicked problem" (Rittel \& Webber 1973, p. 161) and therefore solutions to wicked problems are not true-orfalse but only better-or-worse. This means that the problem and the solution co-evolve in an iterative manner and design of the future concept takes place before the problem is fully understood (Dorst \& Cross 2001). This requires the designer to set priorities early in the process and he/she has to build on only incomplete information. To handle this complexity of the situation and make sense out of information, the designer applies an abductive strategy. Reasoning through abduction is in design literature generally defined as the core of creativity (Dorst 2015; Dong \& MacDonald 2017; Roozenburg 1993). In abduction, the designer uses hypotheses to argue the best explanation; it is a logic where qualified guesses are allowed and must be tested out along the way. In this sense, abduction is assisted by personal experience and acts as inference or intuition that allows for creation of new knowledge and insight (Kolko 2011). In other words, designers develop hypotheses to make sense of information which enables the designer to see the situation in a new way (Dong \& MacDonald 2017). As such, abductive reasoning is closely related to insight in design (ibid.), whereas ethnography uses analytic induction to generate insights (Atkinson \& Hammersley 2007).

\subsection{General design strategies}

Based on the understanding of the general practices of design, we have now outlined the general strategies for how designers aim to change the existing, how they are driven by solution and the main characteristics of their abductive approach (summarised in Table 2). For this study, we explore the strategies in the context of insight discovering. As such, we explore these 'insight discovery strategies' through the lenses of the designers' general strategies.

Table 2. Designers' general strategies

\begin{tabular}{|l|l|l|}
\hline & Designers' general practice & Designers' general strategies \\
\hline Purpose & Change existing & Search for paradoxes; deconstruction \\
\hline Driver & Solution-driven & Start by defining the desired outcome \\
\hline Logic & Abduction (hypotheses) & $\begin{array}{l}\text { Approach problems as wicked; Co- } \\
\text { development of problem and solution }\end{array}$ \\
\hline
\end{tabular}

\section{RESEARCH DESIGN}

As the aim of this study is to illuminate designers' strategies applied to uncover the key insights that were fundamental to the final outcome, we found that qualitative interviews were the most appropriate research strategy. In this perspective, it is the designer's subjective understanding of the key insights that influenced the outcome that is the central point. To investigate the approaches to insights in the context of expert designers, we studied twelve product cases based on semi-structured interviews with designers in seven different companies. Each interview is audio-recorded, transcribed, and coded through meaning condensation. 


\subsection{Case selection: purposeful sampling strategy}

We used a purposeful-sampling strategy, i.e. cases are selected due to their information-rich nature where key informants are especially important sources on a specialised issue (Patton 2015); in this case the phenomenon of meaningful design insights. Cases are selected based on the experience of the designer (at least 8 years); thus, the type of product is less important as this study focuses on the designer's perspective on the design situation. As such, the informants (designers) were selected based on their representativeness (Eisenhardt \& Graebner 2007) due to their experience in the field, their involvement in the entire design process as well as their key role in decisions made in the process. Cases represent designers mainly in the context of design consultancies due to their acknowledged design-driven approach and experience with development of a variety of products. The companies represented in this study are Designit, Swift Creatives, 3Part, HarritSørensen, Møller-Jensen Design \& Innovation, Steffensen\&Würtz and Coloplast.

\subsection{Data collection: interviews with expert designers}

All interviews are conducted in a face-to-face setting and carried out in the respective company. The purpose of interviews is to enter into expert designers' perspectives, their interpretations, experiences which underlies their approach and how they make sense of the situation; thus, to illuminate what they found meaningful and why, their personal perspective on the design situation, their reasoning behind decisions as well as triggers and drivers in the process. Accordingly, key questions were centred around the design process: what insights were the most important to the project? Why were they important? How are they reflected and translated in the final solution? In most of the cases, the interviews were further supported with project material (e.g. presentations, drawings, briefs, prototypes) to illuminate the process and concept directions during development.

The interviewer was supported with an interview guide with predefined topics of interest to be explored rather than specific questions to be addressed systematically. This strategy allows the interviewer to ask questions spontaneously, dependent on what seems relevant to follow in the particular case (Patton 2015). In this way, the interview guide serves as a checklist to make sure that the same topics are covered across the different cases.

\subsection{Product cases}

The analysis is based on twelve product cases which represent different product categories, mainly in the category of medical products and consumer electronics. This paper will elaborate on only four of these cases to illustrate the findings (due to limited space and to ease understanding). The four cases are introduced in the following and exemplified in section 4.

\subsubsection{Case 1: Hearing aid}

In the hearing aid case, the design team seeks to establish a new way of seeing a hearing aid in contrast to its medical context. Instead of recognising a hearing aid as a medical device, the designers aimed to create a 'superhuman' sound experience. This new understanding of the product was established due to a new law in the US that changes the market conditions for medical devices making it possible to sell these legally in any shop, i.e. on the same conditions as headphones from the market leaders like Apple, Google and Bose. This change forces the company into a highly competitive market of consumer electronics and triggers the focus on the younger generation with hearing loss. But for this user group, a hearing aid is intended for elderly or handicapped people; therefore, getting a hearing aid as a younger person feels as being stigmatised into a context where they do not belong. They are significantly concerned about how they might look with such device. This challenge initiates the focus in the design process: the design team needs to design a hearing aid, but it must absolutely not be seen as one. If it 'helps you hear better' it will be identified as a hearing aid, i.e. a medical device. Therefore, the 'superhuman' identity is established as a steering point to put more excitement, coolness and experience to it as the core values (in contrast to necessity) within the context of consumer electronics. One solution to this was to imitate some interactions with headphones. Another thing was to acquire 'superhuman' skills, which means that you can control surrounding sounds, e.g. in social environments it sorts out the relevant voices, and at home, it connects to your products, e.g. increases the sound from TV and decreases the sound from the cooker hood. 


\subsubsection{Case 2: Catheter for men}

In this case, the design team focuses on creating a new version of the catheter for men which is 'discretely masculine'. The designers had discovered that there are many emotional challenges related to being a user of a catheter, especially from men's point of view. For new users, the long tube feels intimidating which makes insertion hard to overcome. Furthermore, the design team sought to identify the main challenges, which relate to situations where men feel exposed and discretion is therefore a main theme in the design process. To arrive at a product that is recognised as 'discretely masculine', the designers searched for solutions in a male context by looking at existing 'masculine' products' expression (tools, shavers, perfumes etc.) to identify the elements and colours that make them accepted as masculine. Discretion is articulated in the final product as a pocket-size packaging in a fabric-like material that can be safely and tightly closed (without leaking smell or liquids) after use, so it can be kept in the bag or a pocket without drawing attention until a bin is available.

\subsubsection{Case 3: Revolving door}

In this case, the design team found it important to renew the understanding of a revolving door to make an outstanding future product. Instead of regarding a revolving door as an industrial building part, the design team aimed at creating 'an architectural experience'. This perspective is established based on the architects' interpretation of existing revolving doors on the market; from the architects' point of view, a revolving door is regarded as a big grey industrial box that disturbs their architectural work. To achieve 'an architectural experience', the designers sought to specify this meaning. An architectural experience is normally something that people would perceive as a unique product, notice and give attention. Due to this new perspective, the designers identified some main challenges in the existing product experience; people want to pass a revolving door quickly, often due to an uncomfortable feeling of walking through. However, the existing capacity and flow prevents it; it often slows down or even stops when passing. In the 'architectural experience', the revolving door waits for you, it follows your speed and reacts to your movements. Furthermore, the designers seek solution principles where the architect has maximum influence on the expression. Therefore, the final version is a tool/system which is adaptable to different materials, size, lights, etc.

\subsubsection{Case 4: Toy wheelchair}

In this case, the designers' aim was to create a 'toy for children' based on the experience of a wheelchair. The perspective of a wheelchair for fun seemed a bit provocative at that time, as wheelchairs were only intended for people with physical disabilities. The idea was inspired by an observation experienced by the lead designer. The designer had observed his children playing on a wheelchair where they had a lot fun, until their mother intervened in their play and scolded them for playing with a wheelchair. For the designer, this situation was both surprising and offending, and thus it triggered the idea to create a product where it was intended and allowed to have fun on a wheelchair - for any child. The design team searched for solutions with playful elements as seen in institutional toys like moon cars, go-carts and bumper cars. But still it has a clear visual reference to the wheelchair to emphasise 'equal play' for all children, regardless of physical disabilities.

\section{FINDINGS}

In spite of very different innovation levels as well as product categories across the cases, there seems to be a pattern in how designers discover insights. The cases indicate three strategies: Firstly, designers search for insights that could be used to establish the product's future identity. Secondly, designers search for insights that could be used to identify the core challenges in the existing situation based on the new identity. Finally, designers search for insights that could be used to identify relevant solution principles that could both solve the core challenges and emphasise the new identity. The findings are elaborated and exemplified by the product cases in the following.

\subsection{Designers search for insights that could be used to establish the product's future identity}

The cases show that the design teams seek to determine the new product's identity at a very early stage in the design process. Reframing the identity is a critical step for the design team, as it captures a new way of seeing the product and thus a new context in which the new product should be associated. To 
establish the future identity, the design team seeks insights about user, market or societal changes to identify a new opportunity or main challenge that could initiate an idea for a new product experience. Based on their understanding of the situation, they determine the new product identity which becomes the main driver and steering point in the process.

One example of this finding is the case of the revolving door, where the design team changes the identity from 'an industrial building part' into 'an architectural experience'. When the design team gets involved in the project, they seek insights that could provide them with an understanding of stakeholders' interests and values, and how existing doors accommodate these. They identify a main challenge from the architects' point of view: the expression of existing revolving doors is a critical point; existing revolving doors are recognised as an industrial building part, a big, grey box that disturbs their architectural work of art. However, they have no other possibilities if their client wants a revolving door in the building. Thus, the 'architectural experience' captures a new understanding of a revolving door and this new identity becomes the steering point in the design process from where product decisions should be aligned.

Another example of the finding is the toy wheelchair case. In this case, the design team reframed the identity of a wheelchair for handicapped people into 'a toy for children'. The toy identity captures a new meaning of the wheelchair which accordingly initiates a new context for the product. The idea for the new identity is based on an insight discovered by the lead designer. He experienced his children having a lot of fun on a wheelchair but were told not to due to some inherent norms not to play with people's handicap. For the designer, his experience was an opportunity to change this understanding of a wheelchair. Instead of being something that you are only allowed to interact with if you have some disabilities, it was intended to equal children's play and open up children's understanding of people with physical challenges.

\subsection{Based on the new identity, designers search for insights that could be used to identify core challenges in the existing situation}

In the cases, the design teams seek to identify the core challenges in the existing situation that needs to be met in a future solution. In this context, they search for insights related to emotional, social and functional aspects of existing product experiences. The core challenges are mainly identified due to the new understanding of the product; the new product identity captures a new way of seeing the product, which accordingly initiates new challenges that are essential to the new context. This means that core challenges are context-specific and unique to the new situation. Along these lines, the new identity helps the design team to point out critical situations that need to be solved in the future solution.

In the case of developing a catheter for men, the new identity established is 'discretely masculine'. This identity underlies an understanding of a product where absolute discretion is the main goal of the product; or putting it into the designer's words: "the product should not expose the user's situation to people around". Living with a catheter can have many emotional challenges but there seems to be some core dilemmas specifically related to men's situations. Hence, the design team seeks to identify the critical situations of discretion related to men's daily lives, where they would feel exposed or degraded. Core challenges relate to the current size of the catheter which is a long tube for insertion (due to the length of men's urethra) in a long-shaped package. Firstly, many users regard the long tube as very intimidating, which makes insertion very hard to overcome. Secondly, the shape of the package makes it hard to hide unless you carry a bag (which many men do not). Furthermore, there is normally no bin located at men's rooms at public places; therefore, it becomes hard to get rid of the product after use without getting attention. And finally, the scratching sound from the packaging material is not regarded as being discrete from the other side of the toilet stall. In this example, the core challenges are all initiated due to the understanding of 'masculine discretion'.

\subsection{Designers search for insights that could be used to identify relevant solutions that both meet the core challenges and accentuate the new identity}

We further found that the design teams searched for insights that could be used to identify relevant solution principles for the new product. In this process, they intend to specify the new product experience by identifying possible solutions that both meet the core challenges and reflect the new product identity. To accommodate this, the designers seek insight into the new context by investigating interaction principles, expression, features and experiences from other related products in this context. For instance, what is the actual experience of 'superhuman' (hearing aid case) and which 
features does it need in order to be associated within the context of consumer electronics? How are core challenges solved in the 'superhuman' way?

In the hearing aid case, the design team identified that the most critical point is to get the hearing aid product out of the medical context and into the context of consumer electronics. If it indicates that it is a hearing aid, it would fail to accommodate younger people's values. Therefore, the design team searches for principles in the context of consumer electronics that could help the product to be associated within this context. A key principle relates to interaction: when wearing headphones and a person is talking to you, you would lift off the headphones, indicating that you are now listening and ready for conversation. This is an interaction principle that you would normally associate with headphones - not with a hearing aid.

In the case of the revolving door, the design team searched for insights that could help to specify the 'architectural experience'. Therefore, they looked into architectural trends and the architects' values in their work and found that e.g. the architect's choice of materials often changes during a project. In this perspective, they identified that one possible solution principle could be that choice of material and expression of the door should be up to the architect, to fit with the specific context and situation. The core challenges identified from the architectural perspective were that many people felt that passing a revolving door was uncomfortable. This does not match an 'architectural experience' and the design team therefore looks for solutions that could turn passing into something you give attention to. Therefore, they work with light, flow and capacity to make a unique user experience of the revolving door. The designers aim to change the 'dead' object (the industrial building part) into a product with a 'soul': in the future user experience, the door waits for you, start revolving when it sees you and follows your speed and movements.

\section{DISCUSSION AND CONCLUSION}

Discovering novel insights is a fundamental step in the creation of new products. Insights serve as both triggers and drivers for envisioning meaningful experiences to the users, which is critical if the future product is to succeed in accommodating current user values, needs and behaviours. In spite of an increasing amount of literature on methods and tools for information gathering, there has been little discussion in design research on how designers approach this information to discover or uncover key insights in the meaning-making paradigm. In this study, we have explored and encountered three main strategies that designers apply in the insight discovering process: 1) Designers search for insights that could be used to establish the future product identity. 2) Based on the new identity, designers search for insights that could be used to identify the core challenges in the existing situation, and 3) designers search for insights in the future context that could be used to determine possible solutions that might both meet the core challenges and accentuate the new identity (findings summarised in Figure 1). These strategies were identified and explored based on previous research on designers' practice; namely, that designers aim to change the existing, they are solution-driven and they reason through abduction. 


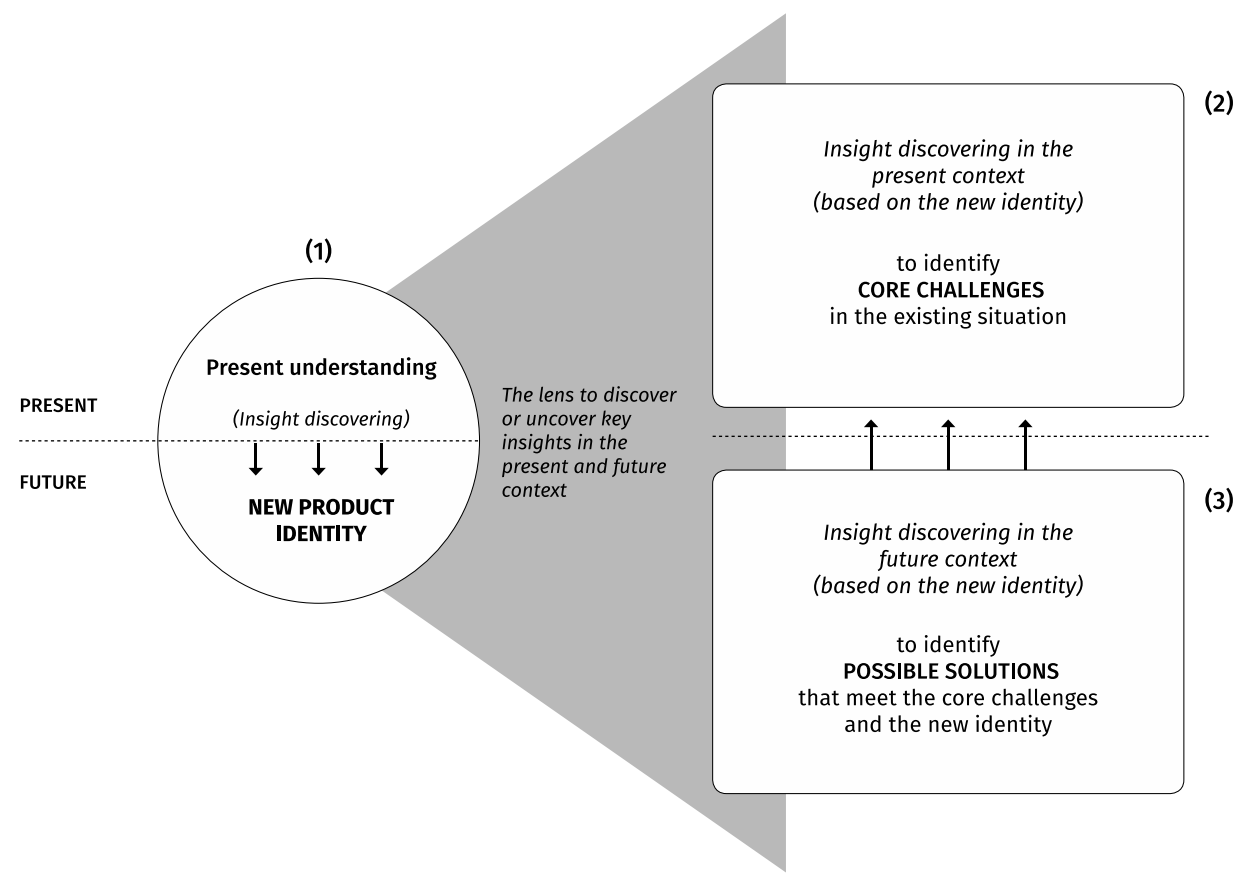

Figure 1. Findings of designers' strategies to discover insights

That designers search for insights to establish the future product identity reflects first of all the abductive strategy in designers' practice. In the abductive strategy, designers develop hypotheses to see things in new ways, but this study indicates that one significant hypothesis focuses on the product identity. This hypothesis (identity) is based on insights from the designer's subjective understanding of the design situation (not empirically true data) which indeed reflects the abductive strategy while it is also a symptom of the solution-driven approach; the identity serves as the aspired goal and the following design process is directed from this goal. Furthermore, the search for a new identity reflects the designer's aim of changing the existing and demonstrates that the current understanding of the product must be reconsidered to change the current situation accordingly. Hence, establishment of the future identity becomes a critical step in the process, as it supports the design team in identifying relevant information as well as decision-making about the product; it serves as a steering point where solutions must be aligned with the intended future state. As such, the following strategies for insight discovering in the design process are initiated based on the new product identity: the designers search for insights that can be used to identify the core challenges $d u e$ to the new identity. Moreover, the challenges must be solved in a way which allows the intended identity to be easily decoded by the user.

\subsection{Implications for further work}

In this study, we have shared our preliminary findings on expert designers' strategies to discover key insights. These findings are based on interviews and must be seen as only preliminary findings; more research is needed to increase understanding of designers' approaches to insights. As such, this study opens up a potential to study designers' expertise in the insight discovery process on a deeper level; by following cases that are emergent we are able to track how insights are used to establish future frames, how these might change during the project, when they are fixed and insights are regarded as 'enough' to develop a meaningful solution. Discovering novel insights is a critical step in design to develop a solution that matters to the users. With this research on designers' expertise, we aim to further increase understanding of the process of making sense of complex information in order to illuminate the real value of design to innovation.

\section{REFERENCES}

Atkinson, P. and Hammersley, M. (2007), Ethnography: Principles in Practice 3rd edition., Taylor \& Francis eLibrary.

van Boijen, A., et al. (2013), Delft Design Guide, BIS Publishers.

Brown, T. (2009), Change by Design: How Design Thinking Transforms Organizations and Inspires Innovation, Harper Business. 
Buijs, J. (2012), The Delft Innovation Method: A Design Thinker's Guide to Innovation, Eleven International Publishing.

Christiaans, H. (1992), Creativity in design. Department of Industrial Design, Phd Thesis.

Cooper, R. and Evans, M. (2006), "Breaking from Tradition : Consumer Needs, and Design Futures", Design Management Review, pp. 68-74.

Cranz, G. (2016), Ethnography for Designers, Taylor \& Francis Ltd, New York.

Cross, N. (2007), Designerly Ways of Knowing, Birkhäuser, Basel, Boston, Berlin.

Csikszentmihalyi, M. and Rochberg-Halton, E. (1981), The Meaning of Things: Domestic Symbols and the Self, Cambridge University Press, Cambridge.

Dong, A. and MacDonald, E. (2017), "From Observations to Insights: The Hilly Road to Value Creation", In: B. T. Christensen, L. J. Ball and K. Halskov, (Ed.), Analysing Design Thinking: Studies of Cross-Cultural Co-Creation, Taylor \& Francis, London, pp. 465-482.

Dorst, K. (2006), “Design Problems and Design Paradoxes”, Design Issues, Vol. 22 No. 3, pp. 4-17.

Dorst, K. 2015. Frame Innovation: Create New Thinking by Design K. Friedman \& E. Stolterman, eds., London, England: The MIT Press.

Dorst, K. and Cross, N. (2001), “Creativity in the design process: Co-evolution of problem-solution”, Design Studies, Vol. 22 No. 5, pp. 425-437.

Dragt, E. (2017), How to Research Trends: Move Beyond Trend Watching to Kickstart Innovation, BIS Publishers, Amsterdam.

Edeholt, H. and Ek, A. (2008), "Research design and the professional model", 5th Interim Conference of the International Sociological Association, pp. 1-14.

Eisenhardt, K. and Graebner, M. (2007), "Theory Building from Cases : Opportunities and Challenges", Academy of Management Journal, Vol. 50 No. 1, pp. 25-32.

Harrison, S., Tatar, D. and Sengers, P. (2007), "The three paradigms of HCI", Alt. Chi. Session at the SIGCHI Conference on Human Factors in Computing Systems San Jose, California, USA, pp. 1-18.

Hekkert, P. and Dijk, M.v. (2011), Vision in Design - A Guidebook for Innovators, BIS Publishers, Amsterdam.

Knudsen, L.S. and Haase, L.M. (2018), "The construction of meaning in design-driven projects: a paradox initiated process", International Journal of Design Creativity and Innovation, pp. 1-15.

Kolko, J. (2011), Exposing the Magic of Design: A Practitioner's Guide to the Methods and Theory of Synthesis, Oxford University Press, New York.

Lawson, B. (2005), How Designers Think: the Design Process Demystified 4th ed., Elsevier Science.

Lee, Y. and Evans, M. (2012), "What drives organisations to employ design-driven approaches? A study of fast moving consumer goods brand development", Design Management Journal, pp. 74-88.

Institute, L.U.M.A. (2012), Innovating for People: Handbook of Human-Centered Design Methods, LUMA Institute, Pittsburgh.

Milton, A. and Rodgers, P. (2013), Research Methods for Product Design, Laurence King Publishing, London.

Miron-Spektor, E., Gino, F. and Argote, L. (2011), "Paradoxical frames and creative sparks: Enhancing individual creativity through conflict and integration", Organizational Behavior and Human Decision Processes, Vol. 116 No. 2, pp. 229-240.

Morrison, A., et al. (2014), "What We Talk About When We Talk About Design", Toward a Taxonomy of Design Competencies. FORMakademisk, Vol. 7 No. 2, pp. 1-17.

Otto, T. and Smith, R.C. (2013), Design Anthropology: A Distinct Style of Knowing. In W. Gunn, T. Otto, \& R. C. Smith, eds. Design Anthropology: Theory and Practice, Bloomsbury, London, England.

Patton, M.Q. (2015), Qualitative Research \& Evaluation Methods 4th revise., SAGE Publications Inc.

Ravasi, D. and Rindova, V.P. (2008), "Symbolic Value Creation", The SAGE Handbook of New Approaches in Management and Organization, pp. 464-466.

Rittel, H.W.J. and Webber, M.M. (1973), "Dilemmas in a general theory of planning”, Policy Sciences, Vol. 4 No. 2, pp. 155-169.

Roozenburg, N. (1993), “On the pattern of reasoning in innovative design”, Design Studies, Vol. 14 No. 1, pp. 4-18.

Schneider, J. and Stickdorn, M. (2011), This Is Service Design Thinking: Basics, Tools, Cases, BIS Publishers, Amsterdam.

Tomitsch, M., et al. (2018), Design. Think. Make. Break. Repeat.: A Handbook of Methods, BIS Publishers, Amsterdam.

Ulwick, A.W. (2005), What Customers Want: Using Outcome-Driven Innovation to Create Breakthrough Products and Services, McGraw-Hill, United States.

Yayici, E. (2016), Design Thinking Methodology Book, Emrah Yayici.

Ylirisku, S., et al. (2009), "Framing Design in the Third Paradigm", Proceedings of the 27th Conference on Human Factors in Computing Systems CHI 2009, ACM, pp. 1131-1140. Available at: https://doi.org/10.1145/1518701.1518874.

Yuan, S.T.D. and Hsieh, P.K. (2015), "Using association reasoning tool to achieve semantic reframing of service design insight discovery”, Design Studies, Vol. 40 No. 64, pp. 143-175. 